Annals of Pure and Applied Mathematics

Vol. 14, No. 2, 2017, 225-229

ISSN: 2279-087X (P), 2279-0888(online)

Published on 30 August 2017

Annals of

www.researchmathsci.org

DOI: http://dx.doi.org/10.22457/apam.v14n2a3

Pure and Applied

Mathematics

\title{
On Nano Generalized $\beta$ Regular Spaces and Nano Generalized $\beta$ Normal Spaces in Nano Topological Spaces
}

\author{
${ }^{I}$ S.B.Shalini, G. Sindhu and K.Indirani \\ Department of Mathematics, Nirmala College for Women, Coimbatore \\ Tamil Nadu, India. \\ ${ }^{1}$ Corresponding author. Email: shal.manogar@gmail.com
}

Received 17 July 2017; accepted 18 August 2017

Abstract. The aim of this paper is to introduce Nano generalized $\beta$ regular spaces and Nano generalized $\beta$ normal spaces in Nano topological spaces and we discuss some of its properties.

Keywords: $\mathrm{Ng} \beta$ regular spaces, $\mathrm{Ng} \beta$ normal spaces.

AMS Mathematics Subject Classification (2010): 18B30

\section{Introduction}

The notion of Nano topology was introduced by Thivagar [4] which was defined in terms of approximations and boundary regions of a subset of an universe using an equivalence relation on it and he also defined Nano closed set, Nano interior and Nano closure. Levine [5] introduced generalized closed sets as a generalization of closed sets in topological spaces. Monsef et al. [1] introduced the notion of $\beta$-open set in topology, and further investigation of Nano $\beta$ open sets was given by Gnanambal [3]. Munshi [6] introduced g-regular and g-normal spaces using g-closed sets in topological spaces. In this paper $\mathrm{Ng} \beta$ regular spaces and $\mathrm{Ng} \beta$ normal spaces are introduced and some of its properties are investigated.

\section{Preliminaries}

Definition 2.1. [4] Let $U$ be the universe, $R$ be an equivalence relation on $U$ and $\tau_{R}(X)=\left\{U, \phi, L_{R}(X), U_{R}(X), B_{R}(X)\right\}$ where $X \subseteq U$. Then it satisfies the following axioms:

i) $\quad U$ and $\phi \in \tau_{R}(X)$.

ii) The union of the elements of any sub collection of $\tau_{R}(X)$ is in $\tau_{R}(X)$.

iii) The intersection of the elements of any finite sub collection of $\tau_{R}(X)$ is in $\tau_{R}(X)$. 
S.B.Shalini, G. Sindhu and K.Indirani

Then $\tau_{R}(X)$ is called the Nano topology on $U$ with respect to $X,\left(U, \tau_{R}(X)\right)$ is called the Nano topological space. Elements of the Nano topology are known as Nano open sets in $U$. Elements of $\left[\tau_{R}(X)\right]^{C}$ are called Nano closed sets in $U$.

Definition 2.2. [4] If $\left(U, \tau_{R}(X)\right)$ is a Nano topological space with respect $X$ where $X \subseteq U$ and if $A \subseteq U$, then

- The Nano interior of a set $A$ is defined as the union of all Nano open subsets contained in $A$ and is denoted by $N \operatorname{int}(A) . N \operatorname{int}(A)$ isthe largest Nano open subset of $A$.

- The Nano closure of a set $A$ is defined as the intersection of all Nano closed sets containing $A$ and is denoted by $N c l(A) . N \operatorname{Nol}(A)$ is the smallest Nano closed set containing $A$.

Definition 2.3. [2] A subset $A$ of $\left(U, \tau_{R}(X)\right)$ is called Nano generalized closed set (briefly $\mathrm{Ng}$ closed) if $N c l(A) \subseteq V$ whenever $A \subseteq V$ and $V$ is Nano open in $\left(U, \tau_{R}(X)\right)$.

Definition 2.4. [7] A subset $A$ of Nano topological space $\left(U, \tau_{R}(X)\right)$ is called Nano generalized $\beta$ closed set (briefly $\mathrm{Ng} \beta$ closed) if $N \beta c l(A) \subseteq V$ whenever $A \subseteq V$ and $V$ is Nano open in $\left(U, \tau_{R}(X)\right)$.

Definition 2.5. [8] Let $\left(U, \tau_{R}(X)\right)$ and $\left(V, \sigma_{R^{\prime}}(Y)\right)$ be Nano topological spaces. Then a mapping $f:\left(U, \tau_{R}(X)\right) \rightarrow\left(V, \sigma_{R^{\prime}}(Y)\right)$ is called $\mathrm{Ng} \beta$ continuous on $U$ if the inverse image of every Nano open set in $V$ is $\mathrm{Ng} \beta$ open in $U$.

Definition 2.6. [8] Let $\left(U, \tau_{R}(X)\right)$ and $\left(V, \sigma_{R^{\prime}}(Y)\right)$ be Nano topological spaces. Then a mapping $f:\left(U, \tau_{R}(X)\right) \rightarrow\left(V, \sigma_{R^{\prime}}(Y)\right)$ is called $\mathrm{Ng} \beta$ irresolute on $U$ if the inverse image of every $\operatorname{Ng} \beta$ closed set in $V$ is $\operatorname{Ng} \beta$ closed in $U$.

Definition 2.7. [8] A map $f:\left(U, \tau_{R}(X)\right) \rightarrow\left(V, \sigma_{R^{\prime}}(Y)\right)$ is said to be $\mathrm{Ng} \beta$ closed map on $U$ if the image of every Nano closed set in $U$ is $\mathrm{Ng} \beta$ closed in $V$.

Definition 2.8. [8] A map $f:\left(U, \tau_{R}(X)\right) \rightarrow\left(V, \sigma_{R^{\prime}}(Y)\right)$ is said to be strongly $\mathrm{Ng} \beta$ closed map on $U$ if the image of every $\mathrm{Ng} \beta$ closed set in $U$ is $\mathrm{Ng} \beta$ closed in $V$.

\section{3. $\mathrm{Ng} \beta$ regular spaces and $\mathrm{Ng} \beta$ normal spaces}


On Nano Generalized $\beta$ Regular Spaces and Nano Generalized $\beta$ Normal Spaces in Nano Topological Spaces

Definition 3.1. A Nano topological space $\left(U, \tau_{R}(X)\right)$ is said to be $\mathrm{Ng} \beta$ regular space, if for each Nano closed set $F$ and each point $x \notin F$, there exists disjoint $\mathrm{Ng} \beta$ open sets $G$ and $H$ such that $x \in G$ and $F \subset H$.

Remark 3.2. Every Nano regular space is $\mathrm{Ng} \beta$ regular space.

Theorem 3.3. If $f: U \rightarrow V$ is Nano continuous bijective, $\operatorname{Ng} \beta$ open function and $U$ is a Nano regular space then $V$ is $\mathrm{Ng} \beta$ regular.

Proof: Let $F$ be a Nano closed set in $V$ and $y \notin F$. Take $y=f(x)$ for some $x \in U$. Since $f$ is Nano continuous, $f^{-1}(F)$ is Nano closed in $U$ such that $x \notin f^{-1}(F)$. Now $U$ is Nano regular space, there exist disjoint Nano open sets $G$ and $H$ such that $x \in G$ and $f^{-1}(F) \subset H$. That is $y=f(x) \in f(G)$ and $F \subset f(H)$. Since $f$ is $\mathrm{Ng} \beta$ open function, $f(G), f(H)$ are $\mathrm{Ng} \beta$ open sets in $V$ and $f$ is bijective, $f(G) \cap f(H)=$ $f(G \cap H)=f(\phi)=\phi$. Therefore $V$ is $\mathrm{Ng} \beta$ regular space.

Theorem 3.4. If $f: U \rightarrow V$ is Nano continuous surjective, strongly $\operatorname{Ng} \beta$ open function and $U$ is a $\mathrm{Ng} \beta$ regular then $V$ is also $\mathrm{Ng} \beta$ regular.

Proof: Let $F$ be a Nano closed set in $V$ and $y \notin F$. Take $y=f(x)$ for some $x \in U$. Since $f$ is Nano continuous surjective, $f^{-1}(F)$ is Nano closed in $U$ such that $x \notin f^{-1}(F)$. Now $U$ is $\mathrm{Ng} \beta$ regular, there exist disjoint $\mathrm{Ng} \beta$ open sets $G$ and $H$ such that $x \in G$ and $f^{-1}(F) \subset H$. That is $y=f(x) \in f(G)$ and $F \subset f(H)$. Since $f$ is strongly $\mathrm{Ng} \beta$ open and surjective, $f(G), f(H)$ are disjoint $\mathrm{Ng} \beta$ open sets in $V$. Therefore $V$ is $\mathrm{Ng} \beta$ regular space.

Theorem 3.5. If $f: U \rightarrow V$ is $\operatorname{Ng} \beta$ continuous, Nano closed injection and $V$ is a Nano regular space then $U$ is $\mathrm{Ng} \beta$ regular.

Proof: Let $F$ be a Nano closed set in $U$ and $x \notin F$. Since $f$ is Nano closed injection, $f(F)$ is Nano closed set in $V$ such that $f(x) \notin f(F)$. Now $V$ is Nano regular, there exist disjoint Nano open sets $G$ and $H$ such that $f(x) \in G$ and $f(F) \subset H$. This implies $x \in f^{-1}(G)$ and $\quad F \subset f^{-1}(H)$. Since $\quad f$ is $\operatorname{Ng} \beta$ continuous function, $f^{-1}(G), f^{-1}(H)$ are $\operatorname{Ng} \beta$ open sets in $U$. Further, $f^{-1}(G) \cap f^{-1}(H)=\phi$. Hence $U$ is $\mathrm{Ng} \beta$ regular space.

Theorem 3.6. If $f: U \rightarrow V$ is $\mathrm{Ng} \beta$ irresolute, Nano closed injection and $V$ is a $\mathrm{Ng} \beta$ regular then $U$ is also $\mathrm{Ng} \beta$ regular. 
S.B.Shalini, G. Sindhu and K.Indirani

Proof: Let $F$ be a Nano closed set in $U$ and $x \notin F$. Since $f$ is Nano closed injection, $f(F)$ is Nano closed set in $V$ such that $f(x) \notin f(F)$. Now $V$ is Nano regular, there exist disjoint Nano open sets $G$ and $H$ such that $f(x) \in G$ and $f(F) \subset H$. This implies $x \in f^{-1}(G)$ and $F \subset f^{-1}(H)$. Since $f$ is $\mathrm{Ng} \beta$ irresolute, $f^{-1}(G), f^{-1}(H)$ are $\mathrm{Ng} \beta$ open sets in $U$. Further, $f^{-1}(G) \cap f^{-1}(H)=\phi$. Hence $U$ is $\mathrm{Ng} \beta$ regular space.

Definition 3.7. A Nano topological space $\left(U, \tau_{R}(X)\right)$ is said to be $\mathrm{Ng} \beta$ normal space, if for each pair of disjoint Nano closed sets $E$ and $F$ of $U$, there exists disjoint $\mathrm{Ng} \beta$ open sets $G$ and $H$ such that $E \subset G$ and $F \subset H$.

Remark 3.8. Every Nano normal space is $\mathrm{Ng} \beta$ normal space.

Theorem 3.9. If $f: U \rightarrow V$ is Nano continuous bijective, $\operatorname{Ng} \beta$ open function and $U$ is Nano normal space then $V$ is $\mathrm{Ng} \beta$ normal.

Proof: Let $E$ and $F$ be disjoint Nano closed set in $V$. Since $f$ is Nano continuous bijective, $f^{-1}(E)$ and $f^{-1}(F)$ are disjoint Nano closed in $U$. Now $U$ is Nano normal space, there exist disjoint Nano open sets $G$ and $H$ such that $f^{-1}(E) \subset G$ and $f^{-1}(F) \subset H$. That is $E \subset f(G)$ and $F \subset f(H)$. Since $f$ is $\mathrm{Ng} \beta$ open function, $f(G), f(H)$ are $\mathrm{Ng} \beta$ open sets in $V$ and $f$ is injective, $f(G) \cap f(H)=$ $f(G \cap H)=f(\phi)=\phi$. Therefore $V$ is $\mathrm{Ng} \beta$ normal space.

Theorem 3.10. If $f: U \rightarrow V$ is $\operatorname{Ng} \beta$ continuous, Nano closed injection and $V$ is a Nano normal space then $U$ is $\mathrm{Ng} \beta$ normal.

Proof: Let $E$ and $F$ be disjoint Nano closed set in $V$. Since $f$ is Nano closed injection, $f(E)$ and $f(F)$ are disjoint Nano closed in $V$. Now $V$ is Nano normal space, there exist disjoint Nano open sets $G$ and $H$ such that $f(E) \subset G$ and $f(F) \subset H$. That is $E \subset f^{-1}(G)$ and $F \subset f^{-1}(H)$. Since $f$ is $\mathrm{Ng} \beta$ continuous function, $f^{-1}(G), f^{-1}(H)$ are $\operatorname{Ng} \beta$ open sets in $U$. Further $f^{-1}(G) \cap f^{-1}(H)=\phi$. Therefore $U$ is $\operatorname{Ng} \beta$ normal space.

Theorem 3.11. If $f: U \rightarrow V$ is $\mathrm{Ng} \beta$ irresolute, Nano closed injection and $V$ is a $\mathrm{Ng} \beta$ normal then $U$ is $\mathrm{Ng} \beta$ normal.

Proof: Let $E$ and $F$ be disjoint Nano closed set in $V$. Since $f$ is Nano closed injection, $f(E)$ and $f(F)$ are disjoint Nano closed in $V$. Now $V$ is $\operatorname{Ng} \beta$ normal space, there exist disjoint $\mathrm{Ng} \beta$ open sets $G$ and $H$ such that $f(E) \subset G$ and $f(F) \subset H$. That is 
On Nano Generalized $\beta$ Regular Spaces and Nano Generalized $\beta$ Normal Spaces in Nano Topological Spaces

$E \subset f^{-1}(G)$ and $F \subset f^{-1}(H)$. Since $f$ is $\mathrm{Ng} \beta$ irresolute, $f^{-1}(G), f^{-1}(H)$ are $\mathrm{Ng} \beta$ open sets in $U$. Further $f^{-1}(G) \cap f^{-1}(H)=\phi$. Therefore $U$ is $\operatorname{Ng} \beta$ normal space.

Theorem 3.12. If $f: U \rightarrow V$ is Nano continuous bijective, strongly $\mathrm{Ng} \beta$ open function and $U$ is $\mathrm{Ng} \beta$ normal then $V$ is also $\mathrm{Ng} \beta$ normal.

Proof: Let $E$ and $F$ be disjoint Nano closed set in $V$. Since $f$ is Nano continuous bijective, $f^{-1}(E)$ and $f^{-1}(F)$ are disjoint Nano closed in $U$. Now $U$ is $\operatorname{Ng} \beta$ normal, there exist disjoint $\operatorname{Ng} \beta$ open sets $G$ and $H$ such that $f^{-1}(E) \subset G$ and $f^{-1}(F) \subset H$. That is $E \subset f(G)$ and $F \subset f(H)$. Since $f$ is strongly $\operatorname{Ng} \beta$ open function, $f(G), f(H)$ are $\mathrm{Ng} \beta$ open sets in $V$ and $f$ is injective, $f(G) \cap f(H)=$ $f(G \cap H)=f(\phi)=\phi$. Therefore $V$ is $\mathrm{Ng} \beta$ normal space.

\section{Conclusion}

In this paper, some of the properties of $\mathrm{Ng} \beta$ regular spaces and $\mathrm{Ng} \beta$ normal spaces are discussed. This shall be extended in the future research with some applications.

\section{REFERENCES}

1. M. E.Abd EL-Monsef, S.N.EL-Deep and R.A.Mahmoud, $\beta$-open sets and $\beta$ continuous mappings, Bull. Fac. Sci., 12 (1983) 77-90.

2. K.Bhuvaneswari and K.Mythili Gnanapriya, Nano generalised closed sets in nano topological spaces, International Journal of Scientific and Research Publications, 4(5) (2014) 1-3.

3. Y.Gnanambal, On Nano $\beta$ open sets, Int. Jr. of Engineering, 1(2) (2015) 1-6.

4. M.L.Thivagar and C.Richard, On Nano forms of weakly open sets, International Journal of Mathematics and Statistics Invention, 1(1) (2013) 31 -37.

5. N.Levine, Generalized closed sets in topology, Rend. Circ. Mat. Palermo, 19(2) (1970) 89-96.

6. B.M.Munshi, Separation axioms, Acta Ciencia Indica, 12 (1986) 140-144.

7. S.B.Shalini and K.Indirani, Characterisation of nano generalized $\beta$ closed sets in nano topological spaces, International Journal of Science and Applied Research, 4(1) (2017) 7-11.

8. S.B.Shalini and K.Indirani, On Nano generalized $\beta$ continuous functions and Nano generalized $\beta$ irresolute functions in Nano topological spaces, IOSR Journal of Mathematics, 13(1) (2017) 79-86.

9. R.S.Wali and V.Dembre, On pre generalized pre regular weakly open sets and pre generalized pre regular weakly neighbourhoods in topological spaces, Annals of Pure and Applied Mathematics, 10(1) (2016) 15-20. 